Lecturer Tanmay SARKAR, PhD

E-mail: tanmays468@gmail.com

Malda Polytechnic, West Bengal State Council of Technical Education Food Technology and Biochemical Engineering, Jadavpur University

Lecturer Molla SALAUDDIN, Post-graduate Student

E-mail: molla8759@gmail.com

Food Technology and Biochemical Engineering, Jadavpur University

Sudipta Kumar HAZRA, Graduate Student

E-mail: sudiptahazra037@gmail.com

Food Technology and Biochemical Engineering, Jadavpur University

Professor Tanupriya CHOUDHURY, PhD

E-mail: Tanupriya@ddn.upes.ac.in

Computer Science, University of Petroleum and Energy Studies

Professor Runu CHAKRABORTY, PHD

E-mail: crunu@hotmail.com

Food Technology and Biochemical Engineering, Jadavpur University

\title{
COMPARATIVE APPROACH OF ARTIFICIAL NEURAL NETWORK AND THIN LAYER MODELLING FOR DRYING KINETICS AND OPTIMIZATION OF REHYDRATION RATIO FOR BAEL (Aegle marmelos (L) correa) POWDER PRODUCTION
}

Abstract. Bael is a seasonal fruit and available in a particular period in year. To study the drying characteristics of bael pulp in the sun, hot-air, microwave, and freeze-drying process thin layer drying models as well as artificial neural network modeling were adopted. The correlation coefficient and the chi-squared test were performed to describe the aptness of models. The response surface methodology (RSM) is one of the most used approaches cultivated in the optimization of food processing technology. One of met heuristic algorithms of ubiquitous developed practices is Particle Swarm Optimization (PSO), which is frequently experienced in finding the optimized elucidation of a problem. This study focused on the comparative predictive ability of process condition optimization to yield bael powder with the highest rehydration ratio. The results showed that PSO contributed an improved rehydration ratio yield for optimal input process parameters during bael powder production through different cutting edge drying methods.

Keywords: Kinetics modeling, Machine learning, Food Processing, Response surface methodology, Particle Swarm Optimization.

JEL Classification: P28, O13, L66, Q16

DOI: 10.24818/18423264/55.1.21.11 
Tanmay Sarkar, Molla Salauddin, Sudipta Kumar Hazra, Tanupriya Choudhury, Runu Chakraborty

\section{Introduction}

Bael (Aegle marmelos (L) correa) is a subtropical fruit that belongs to Rutaceae family. Abundant cultivation if bael is seen in Southeast Asia. Owing to its delicious taste and plenty of medicinal benefits it is largely taken as fresh fruit or can be made to some products like syrups and powder (Hazra 2020). Rehydration ratio is found to be the most important parameter in understanding the drying characteristic of bael fruit. The drying methods employed and other process parameters have a great impact on the dried product's quality.

Very often semi theoretical and empirical model fitting is studied by researchers for drying kinetics prediction of food material (Onwude 2016). Nonlinear interactions can be predicted better through an artificial neural network (ANN); the input-output relationship is competitively learned by the ANN tool by simulating the neural system of the human being. ANN was employed by researchers to study the drying behavior of bael (Dash 2020). Microwave vacuum drying of bael was investigated by Dash et al., 2020 (Dash 2020). The comparative study of ANN and empirical modeling was very limited, especially for bael, very little or no investigation was there for the sun and freeze-drying kinetics.

Response surface methodology is an approximation method that utilizes statistical techniques in solving complex designs. Appropriate response values can be produced by the optimization of the variables. RSM technique used previously in the optimization of hot air drying of mango (Sarkar 2021) and microwave drying of apple slices and button mushroom (Han 2010). Besides all these advantages RSM cannot be used in cases where more complex relationship found between process variables and responses as the number of variables increases. Like RSM, particle swarm optimisation (PSO) method also contributes to the optimisation of designs consisting multivariables. This method is inspired by swarm behaviour of bird flocking and movement dynamics of insects and fish. A particle in the algorithm is represented by a bird, in search of optimal location the particle traverse in hyper dimensional space. Not only that the position of particles alters to find the best position of its own and also for neighbours.

This study shows the comparison between ANN and thin layer drying kinetics model for describing the dehydration behaviour as well as RSM and PSO on rehydration ratio for various drying techniques of bael fruit namely hot-air drying, microwave assisted drying, freeze-drying and sun drying.

\section{Materials \& methods}

2.1. Preparation of sun dried (BS), hot air dried (BH), freeze dried (BF) and microwave dried bael (BM) sample

The Central Composite Design was adapted to accomplish the drying (data not presented) where the independent variables were screen opening (4-6 mesh) and homogenization time $(30-60 \mathrm{sec})$ for all four types of drying methods, while for $\mathrm{BH}$ 
Comparative Approach of Artificial Neural Network and Thin Layer Modelling for Drying Kinetics and Optimization of Rehydration Ratio for Bael (Aegle marmelos (L) correa) Powder Production

drying temperature $\left(60-80^{\circ} \mathrm{C}\right)$ and $\mathrm{BM}$ microwave power level (100-300 watt) were another two important independent variables for respective drying methods. Preliminary tests were done in determining the input variables ranges. All the dried samples were individually poured in an electric blender (Prestige Stylo, Serial no. 9B 4030, $2800 \mathrm{rpm}$ ) and mixed for 30 to $60 \mathrm{sec}$ to get the powdered sample.

\subsection{Dehydration Kinetics}

The following equation was used to determine the moisture ratio $\left(\mathrm{M}_{\mathrm{R}}\right)$ for each drying of bael.

$$
\mathrm{M}_{\mathrm{R}}=\frac{M-M_{e q}}{M_{\text {ini }}-M_{\text {equ }}}
$$

Where, $\mathbf{M}_{\text {ini }}, \mathbf{M}$, and $\mathbf{M}_{\text {equ }}=$ moisture content of bael pulp at initially, time $t$, and equilibrium moisture content.

The equation for unsteady sate moisture diffusion of infinite slab (Dash et al., 2020) can be represented as following; assuming temperature and effective moisture diffusivity were constant, only diffusion was there with negligible shrinkage of bael pulp.

$$
\mathrm{M}_{\mathrm{R}}=\frac{8}{\pi^{2}} \sum_{n=1}^{\infty} \frac{1}{(2 A-1)^{2}} e^{\left[-\frac{\left.(2 A-1)^{2} \pi^{2} D_{e m} t\right)}{4 H^{2}}\right]}
$$

Where, $\mathrm{A}, \mathrm{D}_{\mathrm{em}}$ and $\mathrm{H}$ represent positive integer, effective moisture diffusivity and sample half thickness $(0.16 \mathrm{~cm}$.), the first portion of the equation (logarithmic form)

(3) can be expressed as:

$\ln \left(\mathrm{M}_{\mathrm{R}}\right)=\ln \frac{8}{\pi^{2}}-\left(\frac{\pi^{2} D_{e m} t}{4 H^{2}}\right)$

$\mathrm{D}_{\mathrm{em}}$ was determined from the plot of $\ln (\mathrm{MR})$ and drying time (t) from the following equation:

$\mathrm{D}_{\mathrm{em}}=-\frac{\text { Slope } 4 H^{2}}{\pi^{2}}$

Thirteen semi-theoretical and empirical models (Table 1) were considered to study the drying characteristics of bael pulp in different drying techniques. ANN model was developed using MATLAB R2014b (MathWorks Inc., USA).

\subsection{Rehydration ratio}

Rehydration ratio (RR) was measured following the method referred by Adiletta (2018) with some adjustment. 1g. of sample was dissolved in $10 \mathrm{~g}$. of distilled water at temperatures of $60{ }^{\circ} \mathrm{C}$, with rigours stirring for 20 minutes. The following equation was used in the calculation of RR (5).

$$
\mathrm{RR}=\frac{U_{R h}}{U}
$$

Where, $\mathrm{U}$ and $\mathrm{U}_{\mathrm{Rh}}=$ mass of bael powder before and after rehydration (g.)

DOI: $10.24818 / 18423264 / 55.1 .21 .11$ 
Tanmay Sarkar, Molla Salauddin, Sudipta Kumar Hazra, Tanupriya Choudhury, Runu Chakraborty

\subsection{Response Surface Methodology (RSM) optimization}

Though the experimentations were done in triplicate but documented in average value. The entire data matrixes were studied using the Design-of-Expert software of version 7.0.0 (Statease Inc.; Minneapolis-USA) by considering the CCD model. The mathematical optimization of bael powder processing was anticipated to find the processing variables to maximize RR.

\subsection{Particle Swarm optimization (PSO)}

For PSO, each particles were represented as:

$$
\begin{aligned}
& B_{x}=\left(B_{x 1}, B_{x 2}, B_{x 3} \ldots B_{x z}\right) \text { for } x=1,2,3 \ldots z \\
& E_{x}=\left(E_{x 1}, E_{x 2}, E_{x} \ldots E_{x z}\right) \text { for } x=1,2,3 \ldots z
\end{aligned}
$$

Where, position and velocity represented by $\mathrm{x}_{\mathrm{b}}$ and $\mathrm{v}_{\mathrm{b}}$ respectively.

For each epoch the position $\left(\mathrm{B}_{\mathrm{x}}\right)$ and velocity $\left(\mathrm{E}_{\mathrm{x}}\right)$ for $\mathrm{B}^{\text {th }}$ particle was updated at $(\mathrm{Ep}+1)^{\text {th }}$ as the follows.

$\mathrm{E}_{\mathrm{x}}(\mathrm{Ep}+1)=$ iw. $\mathrm{E}_{\mathrm{x}}(\mathrm{Ep})+\mathrm{A}_{1} \cdot \operatorname{random}_{1} \cdot\left(\mathrm{P}_{\text {lbest }}-\mathrm{B}_{\mathrm{x}}(\mathrm{Ep})\right)+\mathrm{A}_{2} \cdot \operatorname{random}_{2} \cdot\left(\mathrm{P}_{\mathrm{gbest}}-\mathrm{B}_{\mathrm{x}}(\mathrm{Ep})\right)$

$$
\mathrm{B}_{\mathrm{x}}(\mathrm{Ep}+1)=\mathrm{B}_{\mathrm{x}}(\mathrm{k})+\mathrm{E}_{\mathrm{x}}(\mathrm{Ep}+1)
$$

where, $\mathrm{A}_{1}, \mathrm{~A}_{2}$, random $_{1}$, random $_{2}$, iw, $\mathrm{P}_{\text {lbest }}, \mathrm{P}_{\text {gbest }}$ symbolize the coefficients due to acceleration, the random number generated by the system, inertial weight; local best position value, global best fitness value for best particle among the population respectively.

Table 1a. Coefficients and statistical measures for the fitted model

\begin{tabular}{|c|c|l|c|}
\hline SL NO. & Model & \multicolumn{1}{|c|}{ Equation } & Reference \\
\hline 1 & Newton model & MR $=\exp (-\mathrm{kt})$ & El-Beltagy (2007) \\
\hline 2 & Modified Page & MR $=\exp \left[-(\mathrm{Kt})^{\mathrm{n}}\right]$ & Vega (2007) \\
\hline 3 & Handerson and Pabis & $\begin{array}{l}\mathrm{MR}=\mathrm{a} \exp (-\mathrm{kt})+\mathrm{b} \\
\exp (-\mathrm{gt})+\mathrm{c} \exp (-\mathrm{ht})\end{array}$ & Meisami-asl (2009) \\
\hline 4 & Midilli et al. & $\mathrm{MR}=\mathrm{a} \exp (-\mathrm{kt})+\mathrm{bt}$ & Midilli (2002) \\
\hline 5 & Hii et al & $\begin{array}{l}\mathrm{MR}=\mathrm{a} \exp \left(-\mathrm{K}_{1} \mathrm{t}^{\mathrm{n}}\right)+\mathrm{b} \\
\exp \left(-\mathrm{K}_{2} \mathrm{t}^{\mathrm{n}}\right)\end{array}$ & Hii (2009) \\
\hline 6 & Verma & $\begin{array}{l}\mathrm{MR}=\mathrm{a} \exp (-\mathrm{kt})+(1- \\
\mathrm{a}) \exp (-\mathrm{gt})\end{array}$ & Akpinar (2006) \\
\hline 7 & Wang and Singh & $\mathrm{MR}=1+\mathrm{at}+\mathrm{bt}{ }^{2}$ & Omolola (2014) \\
\hline 8 & Modified Midilli & MR $=\mathrm{a} \exp (-\mathrm{kt})+\mathrm{b}$ & Gan(2014) \\
\hline 9 & Peleg & MR $=\mathrm{a} \exp (-\mathrm{kt})+\mathrm{b}$ & $\begin{array}{c}\text { PerieiraDa Silva } \\
(2013)\end{array}$ \\
\hline
\end{tabular}

DOI: 10.24818/18423264/55.1.21.11 
Comparative Approach of Artificial Neural Network and Thin Layer Modelling for Drying Kinetics and Optimization of Rehydration Ratio for Bael (Aegle marmelos (L) correa) Powder Production

\begin{tabular}{|c|c|l|c|}
\hline 10 & $\begin{array}{c}\text { Approximate } \\
\text { Diffusion }\end{array}$ & $\begin{array}{l}\mathrm{MR}=\mathrm{a} \exp (-\mathrm{kt})+(1- \\
\mathrm{a}) \exp (-\mathrm{kbt})\end{array}$ & Yaldiz (2001) \\
\hline 11 & Demir & $\mathrm{MR}=\mathrm{a} \exp (-\mathrm{K} \mathrm{t}) \mathrm{n}+\mathrm{b}$ & Demir (2007) \\
\hline 12 & Two Term Exponential & $\begin{array}{l}\mathrm{MR}=\mathrm{a} \exp \left(-\mathrm{k}_{0} \mathrm{t}\right)+(1 \\
-\mathrm{a}) \exp \left(-\mathrm{k}_{1} \mathrm{a} \mathrm{t}\right)\end{array}$ & Omolola (2014) \\
\hline 13 & Two Term & $\begin{array}{l}\mathrm{MR}=\mathrm{a} \exp \left(-\mathrm{K}_{1} \mathrm{t}\right)+\mathrm{b} \\
\exp \left(-\mathrm{K}_{2} \mathrm{t}\right)\end{array}$ & Dash (2013) \\
\hline
\end{tabular}

Table 1b. Coefficients and statistical measures for the fitted model

\begin{tabular}{|c|c|c|c|c|}
\hline SL NO. & Sun drying & Hot air Drying & Freeze drying & $\begin{array}{l}\text { Microwave } \\
\text { drying }\end{array}$ \\
\hline 1 & $\begin{array}{c}\mathrm{k}=0.00173 \\
\mathrm{R}^{2}=0.98751 \\
\chi^{2}=8.46 \times 10^{-4}\end{array}$ & $\begin{array}{c}\mathrm{k}=0.0042 \\
\mathrm{R}^{2}=0.99186 \\
\chi^{2}=5.82 \times 10^{-4}\end{array}$ & $\begin{array}{c}\mathrm{k}=0.00157 \\
\mathrm{R}^{2}=0.95668 \\
\chi^{2}=0.00368\end{array}$ & $\begin{array}{c}\mathrm{k}=0.08629 \\
\mathrm{R}^{2}=0.99733 \\
\chi^{2}=1.75 \times 10^{-4}\end{array}$ \\
\hline 2 & $\begin{array}{c}\mathrm{k}=0.00176 \\
\mathrm{n}=1.19451 \\
\mathrm{R}^{2}=0.99937 \\
\chi^{2}=4.26 \times 10^{-5}\end{array}$ & $\begin{array}{c}\mathrm{k}=0.00268 \\
\mathrm{n}=1.08247 \\
\mathrm{R}^{2}=0.99392 \\
\chi^{2}=4.35 \times 10^{-4}\end{array}$ & $\begin{array}{c}\mathrm{k}=1.18 \times 10^{-4} \\
\mathrm{n}=1.40607 \\
\mathrm{R}^{2}=0.99433 \\
\chi^{2}=4.82 \times 10^{-4}\end{array}$ & $\begin{array}{c}\mathrm{k}=0.07984 \\
\mathrm{n}=1.03233 \\
\mathrm{R}^{2}=0.99766 \\
\chi^{2}=1.54 \times 10^{-4}\end{array}$ \\
\hline 3 & $\begin{array}{c}\mathrm{a}=12.11535 \\
\mathrm{~b}=6.31 \times 10^{-7} \\
\mathrm{k}=0.00301 \\
\mathrm{c}=-11.1053 \\
\mathrm{~g}=-0.00611 \\
\mathrm{~h}=0.00318 \\
\mathrm{R}^{2}=0.70632 \\
\chi^{2}=0.0199\end{array}$ & $\begin{array}{c}\mathrm{a}=1.02392 \\
\mathrm{~b}=-0.03249 \\
\mathrm{k}=0.00456 \\
\mathrm{c}=4.2810-6 \\
\mathrm{~g}=0.00456 \\
\mathrm{~h}=-0.01955 \\
\mathrm{R}^{2}=0.99719 \\
\chi^{2}=2.01 \times 10^{-4}\end{array}$ & $\begin{array}{c}\mathrm{a}=1.1575 \\
\mathrm{~b}=-0.07875 \\
\mathrm{k}=0.00186 \\
\mathrm{c}=-0.07876 \\
\mathrm{~g}=1.56 \times 10^{-11} \\
\mathrm{~h}=1.56 \times 10^{-11} \\
\mathrm{R}^{2}=0.98561 \\
\chi^{2}=0.00122\end{array}$ & $\begin{array}{c}\mathrm{a}=1.03032 \\
\mathrm{~b}=1.09 \times 10^{-4} \\
\mathrm{k}=0.0912 \\
\mathrm{c}=1.09 \times 10^{-4} \\
\mathrm{~g}=-0.22498 \\
\mathrm{~h}=-0.22501 \\
\mathrm{R}^{2}=0.99893 \\
\chi^{2}=7.06 \times 10^{-5}\end{array}$ \\
\hline 4 & $\begin{array}{c}\mathrm{a}=0.9214 \\
\mathrm{k}=2.60 \times 10^{-9} \\
\mathrm{n}=1.42258 \\
\mathrm{~b}=-\underset{4}{8.93 \times 10^{-}} \\
\mathrm{R}^{2}=0.99965 \\
\chi^{2}=2.41 \times 10^{-5}\end{array}$ & $\begin{array}{c}\mathrm{a}=0.84961 \\
\mathrm{k}=444165.3 \\
\mathrm{n}=-139787 \\
\mathrm{~b}=-0.001703 \\
\mathrm{R}^{2}=0.52987 \\
\chi^{2}=0.03361\end{array}$ & $\begin{array}{c}\mathrm{a}=1.00081 \\
\mathrm{k}=3.51 \times 10^{-5} \\
\mathrm{n}=1.63542 \\
\mathrm{~b}=1.14 \times 10^{-4} \\
\mathrm{R}^{2}=0.99964 \\
\chi^{2}=3.03 \times 10^{-5}\end{array}$ & $\begin{array}{c}\mathrm{a}=1.01131 \\
\mathrm{k}=0.07548 \\
\mathrm{n}=1.11605 \\
\mathrm{~b}=0.00346 \\
\mathrm{R}^{2}=0.99964 \\
\chi^{2}=2.37 \times 10^{-5}\end{array}$ \\
\hline
\end{tabular}


Tanmay Sarkar, Molla Salauddin, Sudipta Kumar Hazra, Tanupriya Choudhury, Runu Chakraborty

\begin{tabular}{|c|c|c|c|c|}
\hline 5 & $\begin{array}{c}\mathrm{a}=1.00947 \\
\mathrm{k}_{1}=5.91 \times 10^{-4} \\
\mathrm{~b}=-0.00947 \\
\mathrm{n}=0.001165 \\
\mathrm{k}_{2}=25.882 \\
\mathrm{R}^{2}=0.99941 \\
\chi^{2}=4.00 \times 10^{-5}\end{array}$ & $\begin{array}{c}\mathrm{a}=1.47185 \\
\mathrm{k}_{1}=0.02386 \\
\mathrm{~b}=-0.47848 \\
\mathrm{n}=0.74571 \\
\mathrm{k}_{2}=0.09205 \\
\mathrm{R}^{2}=0.99848 \\
\chi^{2}=1.08 \times 10^{-4}\end{array}$ & $\begin{array}{c}\mathrm{a}=0.87716 \\
\mathrm{k}_{1}=2.47 \times 10-5 \\
\mathrm{~b}=0.12448 \\
\mathrm{n}=1.70282 \\
\mathrm{k}_{2}=-7.06 \times 10^{-7} \\
\mathrm{R}^{2}=0.99964 \\
\chi^{2}=9.91 \times 10^{-4}\end{array}$ & $\begin{aligned} \mathrm{a} & =0.47401 \\
\mathrm{k}_{1} & =0.10065 \\
\mathrm{~b} & =0.52916 \\
\mathrm{n} & =1.27779 \\
\mathrm{k}_{2} & =0.02334 \\
\mathrm{R}^{2} & =0.99987 \\
\chi^{2} & =8.74 \times 10^{-6}\end{aligned}$ \\
\hline 6 & $\begin{array}{c}\mathrm{a}=1.27257 \\
\mathrm{k}=0.00217 \\
\mathrm{~g}=0.00667 \\
\mathrm{R}^{2}=0.99941 \\
\chi^{2}=4.00 \times 10^{-5}\end{array}$ & $\begin{array}{c}\mathrm{a}=1.0672 \\
\mathrm{k}=0.00453 \\
\mathrm{~g}=0.10285 \\
\mathrm{R}^{2}=0.99663 \\
\chi^{2}=2.41 \times 10^{-4}\end{array}$ & $\begin{array}{c}\mathrm{a}=1.15746 \\
\mathrm{k}=0.00186 \\
\mathrm{~g}=1.77391 \\
\mathrm{R}^{2}=0.98688 \\
\chi^{2}=0.00112\end{array}$ & $\begin{array}{c}\mathrm{a}=1.03057 \\
\mathrm{k}=0.08952 \\
\mathrm{~g}=8016.292 \\
\mathrm{R}^{2}=0.99866 \\
\chi^{2}=8.81 \times 10^{-5}\end{array}$ \\
\hline 7 & $\begin{array}{c}a=-0.00143 \\
b=5.71 \times 10^{-7} \\
R^{2}=0.99803 \\
\chi^{2}=1.33 \times 10^{-4}\end{array}$ & $\begin{array}{c}a=-0.00365 \\
b=4.00 \times 10^{-6} \\
R^{2}=0.99659 \\
\chi^{2}=0.00951\end{array}$ & $\begin{array}{c}a=-0.00123 \\
b=3.78 \times 10^{-7} \\
R^{2}=0.98028 \\
\chi^{2}=0.00168\end{array}$ & $\begin{array}{c}\mathrm{a}=-0.07613 \\
\mathrm{~b}=0.00178 \\
\mathrm{R}^{2}=0.99818 \\
\chi^{2}=1.19 \times 10^{-4}\end{array}$ \\
\hline 8 & $\begin{array}{c}a=1.19219 \\
b=-0.15535 \\
k=0.00143 \\
R^{2}=0.99814 \\
\chi^{2}=1.26 \times 10^{-4}\end{array}$ & $\begin{array}{c}\mathrm{a}=1.022085 \\
\mathrm{~b}=-0.03899 \\
\mathrm{k}=0.00486 \\
\mathrm{R}^{2}=0.99613 \\
\chi^{2}=2.76 \times 10^{-4}\end{array}$ & $\begin{array}{l}\mathrm{a}=1.31396 \\
\mathrm{~b}=-0.2264 \\
\mathrm{k}=0.00125 \\
\mathrm{R}^{2}=0.9874 \\
\chi^{2}=0.0011\end{array}$ & $\begin{array}{c}\mathrm{a}=0.99428 \\
\mathrm{~b}=0.03899 \\
\mathrm{k}=0.09679 \\
\mathrm{R}^{2}=0.99882 \\
\chi^{2}=7.77 \times 10^{-5}\end{array}$ \\
\hline 9 & $\begin{array}{c}a=648.9168 \\
b=0.47563 \\
R^{2}=0.99518 \\
\chi^{2}=3.26 \times 10^{-4}\end{array}$ & $\begin{array}{c}\mathrm{a}=225.1754 \\
\mathrm{~b}=0.65826 \\
\mathrm{R}^{2}=0.98767 \\
\chi^{2}=8.81 \times 10^{-4}\end{array}$ & $\begin{array}{c}\mathrm{a}=800.143 \\
\mathrm{~b}=0.35801 \\
\mathrm{R}^{2}=0.97595 \\
\chi^{2}=0.00204\end{array}$ & $\begin{array}{c}\mathrm{a}=10.79362 \\
\mathrm{~b}=0.66685 \\
\mathrm{R}^{2}=0.99508 \\
\chi^{2}=3.23 \times 10^{-4}\end{array}$ \\
\hline 10 & $\begin{array}{c}\mathrm{a}=-0.27256 \\
\mathrm{~b}=0.32509 \\
\mathrm{k}=0.00667 \\
\mathrm{R}^{2}=0.99941 \\
\chi^{2}=4.00 \times 10^{-5}\end{array}$ & $\begin{array}{c}a=-0.06719 \\
b=0.04399 \\
k=0.10297 \\
R^{2}=0.99663 \\
\chi^{2}=2.41 \times 10^{-4}\end{array}$ & $\begin{array}{c}\mathrm{a}=-0.42257 \\
\mathrm{~b}=0.26407 \\
\mathrm{k}=0.00838 \\
\mathrm{R}^{2}=0.99795 \\
\chi^{2}=1.74 \times 10^{-4}\end{array}$ & $\begin{array}{c}\mathrm{a}=1.000 \\
\mathrm{~b}=-5.73553 \\
\mathrm{k}=0.08679 \\
\mathrm{R}^{2}=0.9974 \\
\chi^{2}=1.71 \times 10^{-4}\end{array}$ \\
\hline 11 & $\begin{array}{c}\mathrm{a}=1.19218 \\
\mathrm{~b}=-0.15535 \\
\mathrm{k}=0.01197 \\
\mathrm{n}=0.11966 \\
\mathrm{R}^{2}=0.99811 \\
\chi^{2}=1.28 \times 10^{-4}\end{array}$ & $\begin{array}{c}\mathrm{a}=1.02088 \\
\mathrm{~b}=0.03894 \\
\mathrm{k}=0.0022 \\
\mathrm{n}=2.20374 \\
\mathrm{R}^{2}=0.99603 \\
\chi^{2}=2.84 \times 10^{-4}\end{array}$ & $\begin{array}{c}\mathrm{a}=1.31401 \\
\mathrm{~b}=-0.22646 \\
\mathrm{k}=0.00354 \\
\mathrm{n}=0.035417 \\
\mathrm{R}^{2}=0.98672 \\
\chi^{2}=0.00113\end{array}$ & $\begin{array}{c}\mathrm{a}=0.99428 \\
\mathrm{~b}=0.03899 \\
\mathrm{k}=0.09838 \\
\mathrm{n}=0.9838 \\
\mathrm{R}^{2}=0.99878 \\
\chi^{2}=8.03 \times 10^{-5}\end{array}$ \\
\hline 12 & $\begin{array}{c}\mathrm{a}=1.27256 \\
\mathrm{k} 0=0.00217\end{array}$ & $\begin{array}{c}\mathrm{a}=1.06721 \\
\mathrm{k} 0=0.00453\end{array}$ & $\begin{array}{c}\mathrm{a}=1.42248 \\
\mathrm{k} 0=0.00221\end{array}$ & $\begin{array}{l}\mathrm{a}=1.03142 \\
\mathrm{k} 0=0.0896\end{array}$ \\
\hline
\end{tabular}


Comparative Approach of Artificial Neural Network and Thin Layer Modelling for Drying Kinetics and Optimization of Rehydration Ratio for Bael (Aegle marmelos (L) correa) Powder Production

\begin{tabular}{|c|c|c|c|c|}
\hline & $\mathrm{k} 1=0.00524$ & $\mathrm{k} 1=0.09636$ & $\mathrm{k} 1=0.00589$ & $\mathrm{k} 1=3.54633$ \\
& $\mathrm{R}^{2}=0.99795$ & $\mathrm{R}^{2}=0.99603$ & $\mathrm{R}^{2}=0.99795$ & $\mathrm{R}^{2}=0.99867$ \\
& $\chi^{2}=1.74 \times 10^{-4}$ & $\chi^{2}=2.41 \times 10^{-4}$ & $\chi^{2}=1.74 \times 10^{-4}$ & $\chi^{2}=8.77 \times 10^{-5}$ \\
\hline \multirow{6}{*}{13} & $\mathrm{a}=0.93859$ & $\mathrm{a}=1.0564$ & $\mathrm{a}=0.99969$ & $\mathrm{a}=1.03032$ \\
& $\mathrm{~b}=0.12408$ & $\mathrm{~b}=4.22 \times 10^{-6}$ & $\mathrm{~b}=0.12395$ & $\mathrm{~b}=6.49 \times 10^{-4}$ \\
& $\mathrm{k} 1=0.00187$ & $\mathrm{k} 1=0.00456$ & $\mathrm{k} 1=0.0018$ & $\mathrm{k} 1=0.0912$ \\
& $\mathrm{k} 2=0.00187$ & $\mathrm{k} 2=-0.01959$ & $\mathrm{k} 2=0.0018$ & $\mathrm{k} 2=0.22518$ \\
& $\mathrm{R}^{2}=0.99493$ & $\mathrm{R}^{2}=0.99663$ & $\mathrm{R}^{2}=0.99795$ & $\mathrm{R}^{2}=0.999$ \\
& $\chi^{2}=3.43 \times 10^{-4}$ & $\chi^{2}=2.41 \times 10^{-4}$ & $\chi^{2}=1.74 \times 10^{-4}$ & $\chi^{2}=6.57 \times 10^{-5}$ \\
\hline
\end{tabular}

\section{Results and Discussion}

Node ' $n$ ' got $M_{R}$ signals from immediate previous layer's node ' $m$ ', all $M_{R}$ signal was connected with ' $\mathrm{W}_{\mathrm{nm}}$ ' bias weight, the effective signal $\left(\mathrm{E}_{\mathrm{n}}\right)$ can be represented as,

$\mathrm{E}_{\mathrm{n}}=\sum_{m_{i}}^{n_{f}} W_{n m} M_{R}$

Here, we considered sigmoid function ranging from 0 to 1 , and expressed as,

$\mathrm{S}=\mathrm{f}\left(\mathrm{E}_{\mathrm{n}}\right)=\frac{1}{1+\mathrm{e}\left(-E_{n}\right)}$

For, output layer ' $\mathrm{O}$ ' with training ' $\mathrm{T}$ ', target $(\mathrm{t})$ is denoted as $\mathrm{t}_{\mathrm{O}}(\mathrm{T})$; input layer ' $\mathrm{I}$ ' with training ' $\mathrm{T}$ ', input (i) is denoted as $\mathrm{i}_{\mathrm{I}}(\mathrm{T})$; hidden layer ' $\mathrm{H}$ ' with training ' $\mathrm{T}$ ', output ' $\mathrm{P}$ ' is denoted as $\mathrm{h}_{\mathrm{H}}(\mathrm{T})$; output layer ' $\mathrm{O}$ ' with training ' $\mathrm{T}$ ', output (o) is denoted as $\mathrm{Oo}(\mathrm{T})$; summation in the weighted form ' $\mathrm{S}$ ' with training ' $\mathrm{T}$ ', for hidden layer input is denoted as $S_{H}{ }^{h}(T)$; summation in the weighted form ' $S$ ' with training ' $T$ ', for hidden layer output is denoted as $S_{O}{ }^{h}(T)$; weighted bias within the input and hidden layer is denoted as $\mathrm{W}_{\mathrm{nm}}{ }^{\mathrm{H}}$; weighted bias within hidden node and output layer is denoted as $\mathrm{W}_{\mathrm{On}}{ }^{\mathrm{H}}$.

The total number of input and output layers was considered as A sets, where each set consists of $\mathrm{x}$ and $\mathrm{y}$ numbers of input and output variables respectively. Each input was expressed as $[\mathrm{n} 1(\mathrm{~T}), \mathrm{n} 2(\mathrm{~T}), \ldots, \mathrm{nx}(\mathrm{T})]^{\text {total }}$, whereas, output was expressed as $[\mathrm{p} 1(\mathrm{~T}), \mathrm{p} 2(\mathrm{~T}), \ldots, \mathrm{py}(\mathrm{T})]^{\text {total }}$, similarly target was expressed as $[\mathrm{g} 1(\mathrm{~T}), \mathrm{g} 2(\mathrm{~T}), \ldots, \mathrm{gy}(\mathrm{T})]$ total. The Sum of squared error (SSE) was then expressed as follows.

$\mathrm{F}(\mathrm{w})=\frac{1}{2} \sum_{T=1}^{A} \sum_{O=1}^{y}\left(\mathrm{t}_{O}(\mathrm{~T})-\mathrm{o}_{O}(\mathrm{~T})\left(\mathrm{t}_{O}(\mathrm{~T})-\mathrm{o}_{O}(\mathrm{~T})=\right.\right.$

$$
=\frac{1}{2} \sum_{O=1}^{A} \sum_{O=1}^{y}\left(\mathrm{t}_{O}(\mathrm{~T})-\mathrm{f}\left(\sum_{H=0}^{y} W_{O n}^{H} f\left(\sum_{j=0}^{n 0} W_{n m}^{H} i_{I}(T)\right)\right)\left(\mathrm{t}_{O}(\mathrm{~T})-\right.\right.
$$

$\mathrm{f}\left(\sum_{H=0}^{y} W_{O n}^{H} f\left(\sum_{j=0}^{n 0} W_{n m}^{H} i_{I}(T)\right)\right)$

The backward transformation of T (target) in output (O) can be expressed as,

DOI: $10.24818 / 18423264 / 55.1 .21 .11$ 
Tanmay Sarkar, Molla Salauddin, Sudipta Kumar Hazra, Tanupriya Choudhury, Runu Chakraborty

$\mathrm{TE}_{\mathrm{Ov}}(\mathrm{T})=\log \left(\frac{t_{O}(T)}{1-t_{O}(T)}\right)$

The new SSE for target value after transformation is expressed as,

$\mathrm{F}_{\text {new }}(\mathrm{w})=\frac{1}{2} \sum_{T=1}^{A} \sum_{O=1}^{y}\left(T E_{O}(\mathrm{~T})-S_{H}^{h}(\mathrm{~T})\right)\left(T E_{O}(\mathrm{~T})-S_{H}^{h}(\mathrm{~T})\right)$

$=\frac{1}{2} \sum_{O=1}^{A} \sum_{O=1}^{y}\left(T E_{O}(\mathrm{~T})-\mathrm{f}\left(\sum_{H=0}^{y} W_{O n}^{H} f\left(\sum_{j=0}^{n 0} W_{n m}^{H} i_{I}(T)\right)\right)\left(T E_{O}(\mathrm{~T})-\right.\right.$

$\mathrm{f}\left(\sum_{H=0}^{y} W_{O n}^{H} f\left(\sum_{j=0}^{n 0} W_{n m}^{H} i_{I}(T)\right)\right)$

The first order derivative of $\mathrm{F}_{\text {new }}$ is zero, therefore,

$\sum_{T=1}^{A}\left(T E_{O}(\mathrm{~T}) \mathrm{y}_{H}(\mathrm{~T})=\sum_{O=1}^{A} \sum_{O=1}^{y} \mathrm{f}\left(\sum_{H=0}^{y} W_{O n}^{H} f\left(\sum_{j=0}^{n 0} W_{n m}^{H} i_{I}(T)\right) \mathrm{y}_{H}(\mathrm{~T})\right)\right.$

Solving equation (15) the weightage between the hidden and output layer can be derived. Therefore, the output of the hidden layer can be calculated using the following expression:

$I=\frac{2}{1+\exp ^{-2\left(I+T E_{O}(\mathrm{~T})\right)}}-1$

I and $T E_{O}(\mathrm{~T})$ are the hidden layer output criteria and weightage between the hidden and output layers respectively. The predicted $\mathrm{M}_{R}(\mathrm{P})$ was estimated by using the following equation:

$\left.\mathrm{M}_{\mathrm{R}}(\mathrm{P})=T E_{O}(\mathrm{~T})\right) \mathrm{i}_{I}(T)+\mathrm{h}_{H}(\mathrm{~T})$

The efficiency of different empirical model and ANN model were measured using the coefficient of correlation $\left(\mathrm{R}^{2}\right)$ and chi square $\left(\chi^{2}\right)$ analysis, using the following equation.

$\mathrm{R}^{2}=1-\frac{\sum\left(M_{R}(P)-\left(M_{R}(E)\right)^{2}\right.}{\sum_{i=1}^{N}\left(M_{R}(M)-\left(M_{R}(E)\right)^{2}\right.}$

$\chi^{2}=\frac{\sum_{0}^{\alpha} M_{R}(E)-M_{R}(P) M_{R}(E)-M_{R}(P)}{\text { Number of observation-Number of model constant }}$

Where, $M_{R}(E)$ and $M_{R}(M)$ are the experimental and mean moisture ratios respectively.

It can be stated that during drying when a uniformly distributed layer of material gets full exposure to airstream then it is described as thin-layer drying. The layer thickness should be limited to three layers of bael pulp and owing to uniformity of thickness temperature distribution was also considered to be uniform. Diffusion proved to be the dominant drying mechanism for fruits and vegetables rather than other drying mechanisms like capillary action. Moisture content of the bael sample and also its characteristics had a great impact on the rate of diffusion. On the other hand rate of drying largely depend on the rate of diffusion. In developing the drying kinetics modeling it was necessary to identify the dominant drying mechanism, in depicting the drying phases of fruits and vegetables there were so many evidences which concluded that a negligible initial constant rate period was found while most of the drying had been found to occur during falling rate period. Two models namely, distributed element model and lumped element model were commonly utilized in modeling the 
Comparative Approach of Artificial Neural Network and Thin Layer Modelling for Drying Kinetics and Optimization of Rehydration Ratio for Bael (Aegle marmelos (L) correa) Powder Production

drying process. In the case of the distributed element model two parameters were taken into consideration time of drying and spatial variables in place of all other dependent parameters. Simultaneous occurrence of heat transfer and mass transfer were observed. The predominant factors were moisture effect and drying temperature rather than pressure effect. On the other hand for the lumped element model only drying time affected the variables. It was assumed that the temperature was constant throughout the drying process. Models used in predicting the drying of fruits and vegetables might be categorized as theoretical, semi theoretical (Newton, Page, Handerson, and Pabis) and empirical (Wang and Singh, Peleg), among these empirical and semi theoretical models offered some benefits like - as these models have relied on experimental data hence fewer assumptions were required, provided a better understanding of drying behavior, and greater extent of accuracy in results. Shrinkage of products and heat transfer phenomena were not taken into consideration in the empirical model. However, theoretical models were considered to have limited use since so many assumptions were made which in turn produced errors in the result. Semi theoretical models were mainly generated either from Fick's law of diffusion or from Newton's law of cooling. As the number of model constant increased these models became more complex to understand though model performance depends on statistical measures (Onwude 2016). The drying parameters modeled and fitted to all the thirteen equations listed in Table 1.

The best-fitted model for BS and BF was Midilli et al., model with the highest $\mathrm{R}^{2}$ of 0.99964 and 0.99965 while the lowest $\chi^{2}$ of $2.41 \times 10^{-5}$ and $3.03 \times 10^{-5}$ respectively. Whereas, Hii et al., model was observed best to determine the drying characteristics for $\mathrm{BH}$ and $\mathrm{BM}$ sample with a maximum $\mathrm{R}^{2}$ value of 0.99848 and 0.99987 along with the lowest $\chi^{2}$ of $1.08 \times 10^{-4}$ and $8.74 \times 10^{-6}$ respectively. Fever leaves, bitter leaves, and Crain-crain leaves drying under direct sun rays were better described by the Midilli model (Alara 2018). Convective drying predicted better by Hii et al. model for pumpkin and carrot (Onwude 2016). Kiwi fruit slice drying were better described by the Midilli model (İşleroğlu 2018).

$M_{R}(E)$ and $M_{R}(P)$ values were virtually in close vicinity for most of the thin layer drying models as well as for the ANN model for different drying processes considered (FIG 1). A total of 1000 iterations were performed to construct the ANN kinetics model for each drying. The learning rate varied from 0.5 to 0.9 for all the drying processes. The architecture for ANN model consist of 1 (input layer) - 5 (hidden layer) - 1 (output layer) for $\mathrm{BS}$ and $\mathrm{BH}$, while the same for $\mathrm{BM}$ and $\mathrm{BF}$ was 1 (input layer) - 2 (hidden layer) - 1 (output layer). Levenberg-Marquardt algorithm was

DOI: $10.24818 / 18423264 / 55.1 .21 .11$ 
Tanmay Sarkar, Molla Salauddin, Sudipta Kumar Hazra, Tanupriya Choudhury, Runu Chakraborty

considered to build an ANN back propagation algorithm for feed-forward neural networks. The correlation coefficient $(\mathrm{R})$ value for the best fitted BS model was 0.99998 (training), 0.99994 (testing), 0.99998 (validation); for the best fitted BH model was 0.99995 (training), 0.99993 (testing), 0.99998 (validation); for the best fitted BM model was 0.99996 (training), 0.99994 (testing), 0.99996 (validation) and 0.99992 (training), 0.99979 (testing), 0.99994 (validation) for the best fitted BF model (Fig. 6-9). The $\mathrm{R}^{2}$ values of the ANN predicted model for BS, BH, BM, and BF was 0.99996, 0.99995, 0.99989, and 0.99994.

In the attainment of final moisture content of $0.39 \mathrm{~kg}$ moisture $/ \mathrm{kg}$ dry basis from initial moisture content $4.86 \mathrm{~kg}$ moisture $/ \mathrm{kg}$ dry basis one of the most common significant phenomena observed among all drying techniques was the absence of constant rate period rather maximum moisture removal happened during falling rate period. Having a uniform layer thickness it was expected to get a uniform temperature distribution throughout the drying of bael pulp (Onwude 2016). The falling rate period of the drying curve is mainly controlled by the parameter effective moisture diffusivity $\left(D_{e m}\right)$, which varied from $31.23 \times 10^{-7} \mathrm{~m}^{2} / \mathrm{s}$ for freeze-drying to $2892.33 \times 10^{-7} \mathrm{~m}^{2} / \mathrm{s}$ in case of microwave drying. Whereas in hot-air drying the observed value of $D_{\text {em }}$ was $172.7 \times 10^{-7} \mathrm{~m}^{2} / \mathrm{sand} 35.13 \times 10^{-7} \mathrm{~m}^{2} / \mathrm{s}$ for sun drying. Surface heating had been observed in the case of convective drying. After initial evaporation from the surface of the bael pulp, subsequently moisture concentration difference forced the water molecules placed in the inner part to get removed. During the final stage of drying, the falling drying rate was noticed which might be explained as the slow diffusion rate of water molecules from the inner portion of the material to surface. In case of sun drying heat and mass transfer occurred simultaneously, water molecules from the interior portion of bael pulp migrated towards the surface in exposure of heat. The initial phase of moisture removal was high but as the moisture got reduced in the product the rate of drying automatically slower down in the later stage. Factors influenced the rate of drying include characteristics of surface (glass), temperature $\left(27 \pm 2^{\circ} \mathrm{C}\right)$ and relative humidity. An extended falling rate was seen in case of sun dried bael powder. Microwave drying involved a shorter drying time (21.30 minutes) and lower consumption of power; it was a potential drying method in retention of nutritional quality of bael. After the initial drying phase the curve showed a fall in drying rate which might be due to the shrinkage at advanced stages compelled the porosity of product to get reduced, which consequently produced a resistance in movement of water. The initial phase of freeze drying did not show any significant reduction in moisture content. In the next phase sublimation of ice brought about most of the water molecules to get sublimated. 
Comparative Approach of Artificial Neural Network and Thin Layer Modelling for Drying Kinetics and Optimization of Rehydration Ratio for Bael (Aegle marmelos (L) correa) Powder Production

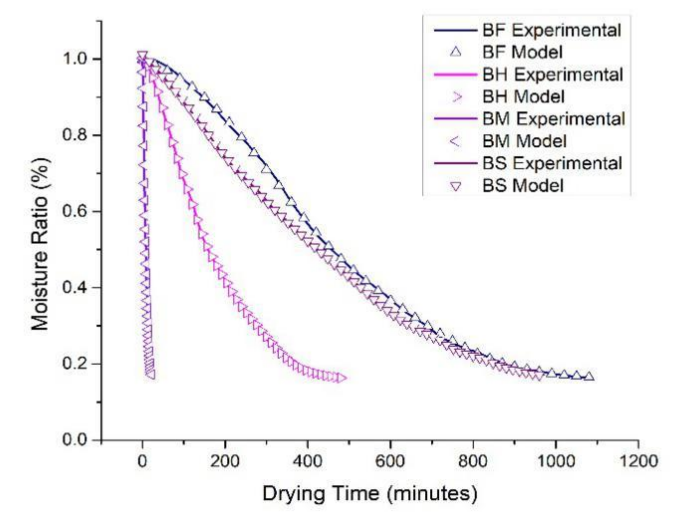

Figure 1. Drying Kinetics of Bael pulp in sun (BS), hot-air (BH, freeze (BF) and Microwave (BM) drying

The maximum RR value was observed for BF (5.52), whereas, the same for $\mathrm{BM}$ gained the minimum of 3.72 to a maximum of 4.71 , RR of 4.71 for $\mathrm{BM}$ was observed under the processing condition of 180-watt microwave power, 6 mesh size (screen opening) and 60 seconds of homogenization time. Similarly, for BS and BH, $\mathrm{RR}$ ranged within 2.6 to 3.39 and 3.08 to 4.53 respectively. At oven temperature of 60 ${ }^{\circ} \mathrm{C}$, homogenization time of 60 seconds and mesh size of 6 the RR value was found highest for $\mathrm{BH}$; The maximum RR for BS was observed at 60 seconds of homogenisation time and mesh size of 6 . RR of the sample was affected significantly $(\mathrm{p}<0.05)$ by hot air oven temperature $\left({ }^{0} \mathrm{C}\right)$, screen opening (mesh size), homogenisation time (seconds) and quadratic effect of oven temperature and homogenisation time (Table 2) (Fig 3 - a, b, c). The model was substantiated significantly through the Fvalue of 17.83. Likewise, $R R$ of $B M$ was significantly $(p<0.05)$ altered by homogenisation time (seconds) and microwave power-level (watt) (Table 2) (Fig 4). Significance of the model was substantiated through the F-value of 85.96 for BM. RR of freeze dried sample were affected significantly by homogenisation time (seconds) and screen opening (mesh size) (Fig 5). Significance of the model was validated through the model F-value of 13.76. The RR for BS was affected by homogenisation time (seconds) and screen opening (mesh size), as well as interaction between screen opening and homogenisation time, in addition to quadratic effects of homogenisation

DOI: $10.24818 / 18423264 / 55.1 .21 .11$ 
Tanmay Sarkar, Molla Salauddin, Sudipta Kumar Hazra, Tanupriya Choudhury, Runu Chakraborty

time (seconds) and screen opening (mesh size) (Fig 2). Significance of the model was substantiated through the F-value of 48.39 for BS. Regression models concerning RR of the bael powder with the processing conditions were achieved for $\mathrm{BS}, \mathrm{BH}, \mathrm{BF}$ and BM satisfied the insignificant ( $p>0.05$ ) lack of fit test with $\mathrm{R}^{2}$ value of $0.9676(\mathrm{BS})$, $0.9413(\mathrm{BH}), 0.7144(\mathrm{BF})$ and $0.9416(\mathrm{BM})$. From predicted model it can be observed that RR was positively affected by screen opening and oven temperature for $\mathrm{BH}$, similarly by screen opening (mesh seize) for BF and BM, and by screen opening for BS sample.

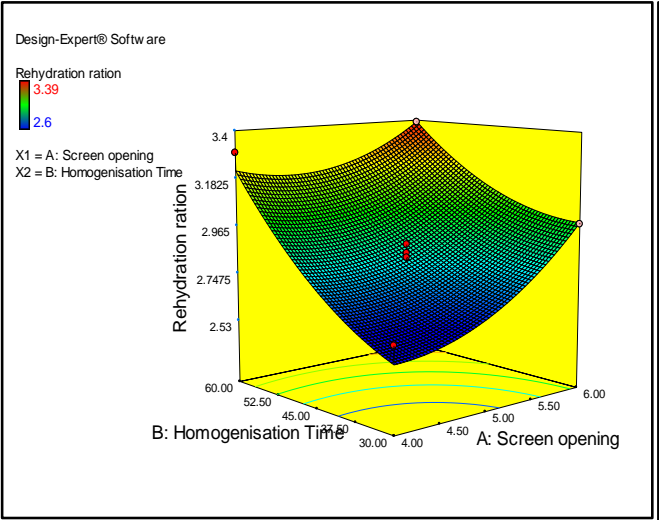

Figure 2. Effect of homogenisation time (B) and Screen opening (A) on rehydration ratio $(R R)$ for Sun Dried

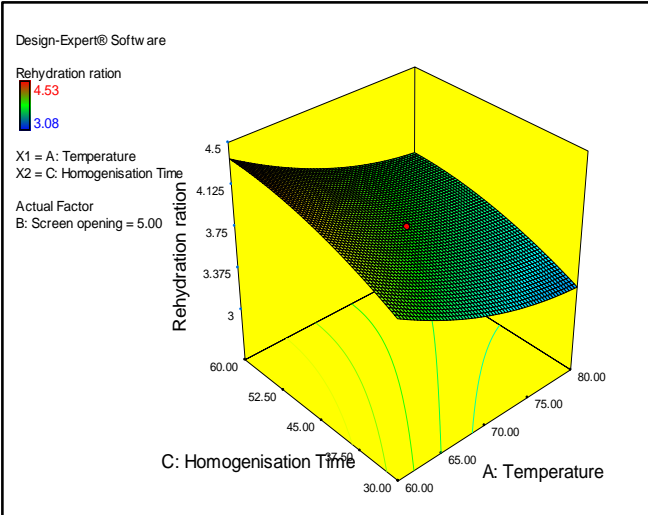

Figure 3a. Effect of homogenisation time $(C)$ and temperature $(A)$ on rehydration ratio (RR) for Hot Dried

The optimized processing inputs obtained through RSM and PSO were virtually similar. Concerning projection capability, RR values predicted by RSM was 3.39 (BS), 4.39(BH), $5.34(\mathrm{BF})$ and $4.63(\mathrm{BM})$ whereas predicted values of RR by PSO was 3.39 (BS), $4.48(\mathrm{BH}), 5.50(\mathrm{BF})$ and $4.69(\mathrm{BM})$. The error in projection for RSM process in optimal process condition were $0.00 \%(\mathrm{BS}), 30.09 \%(\mathrm{BH}), 3.26 \%(\mathrm{BF})$ and $0.72 \%$ (BM), the same for and PSO method were 
Comparative Approach of Artificial Neural Network and Thin Layer Modelling for Drying Kinetics and Optimization of Rehydration Ratio for Bael (Aegle marmelos (L) correa) Powder Production

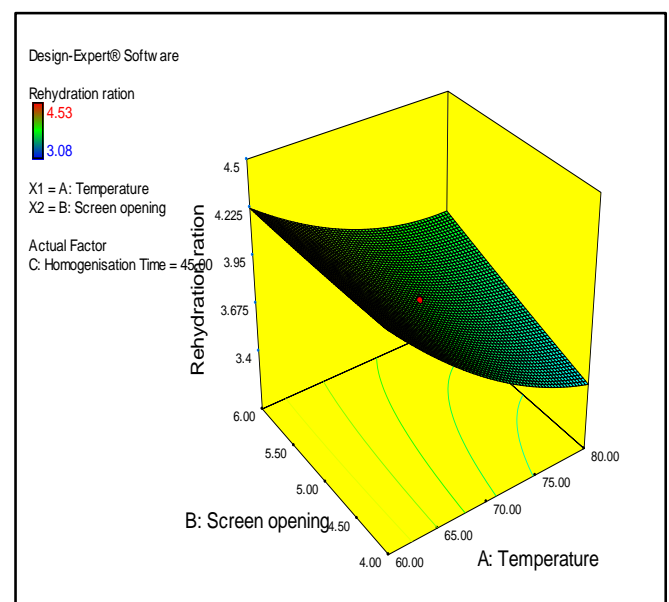

Fig. 3b. Effect of screen opening (B) and temperature $(A)$ on rehydration ratio (RR) for Hot Air Dried bael (BH)

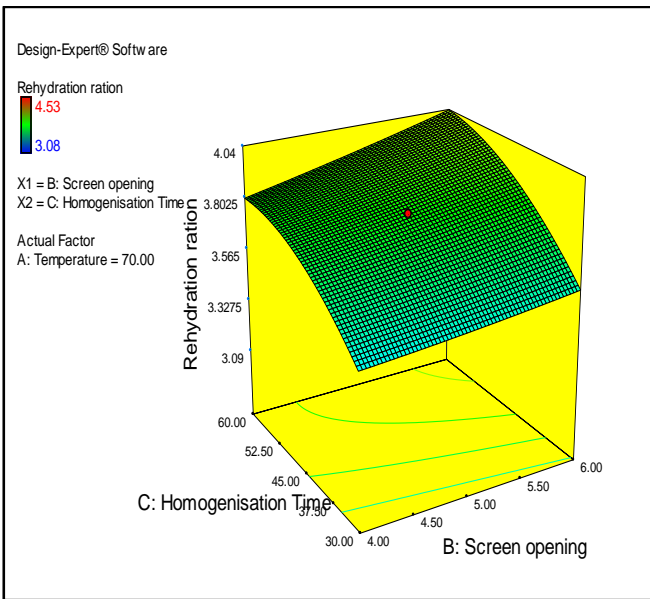

Fig. 3c. Effect of homogenisation time (C) and Screen opening (B) on rehydration ratio (RR) for Hot Air Dried bael (BS)

$0.00 \%(\mathrm{BS}), 1.10 \%(\mathrm{BH}), 0.36 \%(\mathrm{BF})$ and $0.24 \%(\mathrm{BM})$ respectively. The value of the correlation coefficient $\left(\mathrm{R}^{2}\right) \geq 0.75$ is generally treated as a parameter for the construction of a robust model. PSO fits the investigational observations with better compared to RSM. The $\mathrm{R}^{2}$ values obtained for BS, BH, BF and BM were 0.9676, $0.9413,0.7144,0.9416$ and $0.9937,0.9915,0.9751$ and 0.9878 attained from RSM process (Fig. 2-5) and PSO methodology (Fig. 6-9) respectively. The RSM and PSO method constructed an effective model, though the projection accomplishment was more for PSO than RSM in this study. Convergence criteria were completed in less than 80 iterations for $\mathrm{BS}, \mathrm{BH}, \mathrm{BF}$, and $\mathrm{BM}$. The elapsed time required to complete the convergence for $\mathrm{BS}, \mathrm{BH}, \mathrm{BF}$, and $\mathrm{BM}$ were 1.520142, 40.443038, 1.093933, and 1.089084 seconds respectively. May be due to the convoluted quadratic interaction between the model's criteria, a relatively complex model was constructed for BH resulted in a larger convergence time requirement. RSM model was not fitted well in the case of BF though the PSO technique generates an $\mathrm{R}^{2}$ value of 0.9751 .

DOI: $10.24818 / 18423264 / 55.1 .21 .11$ 
Tanmay Sarkar, Molla Salauddin, Sudipta Kumar Hazra, Tanupriya Choudhury, Runu Chakraborty

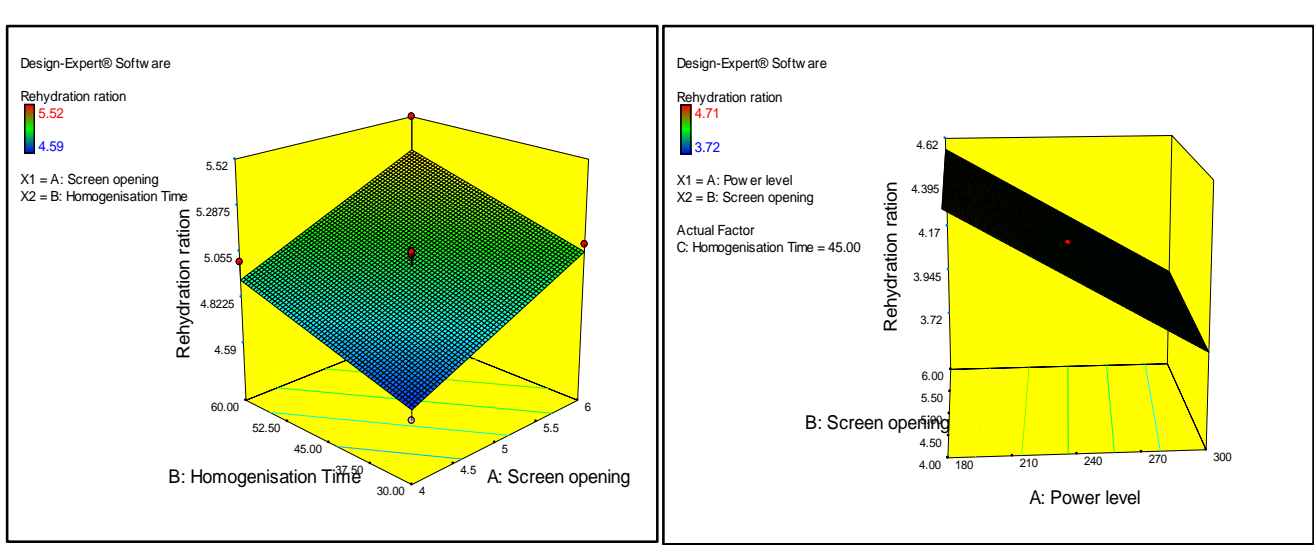

Fig. 4. Effect of homogenisation time

Fig. 5. Effect of Screen opening (B)

(B) and Screen opening (A) on and Power level (A) on rehydration rehydration ratio (RR) for Microwave Dried bael (BM) ratio (RR) for Freeze Dried bael (BF)
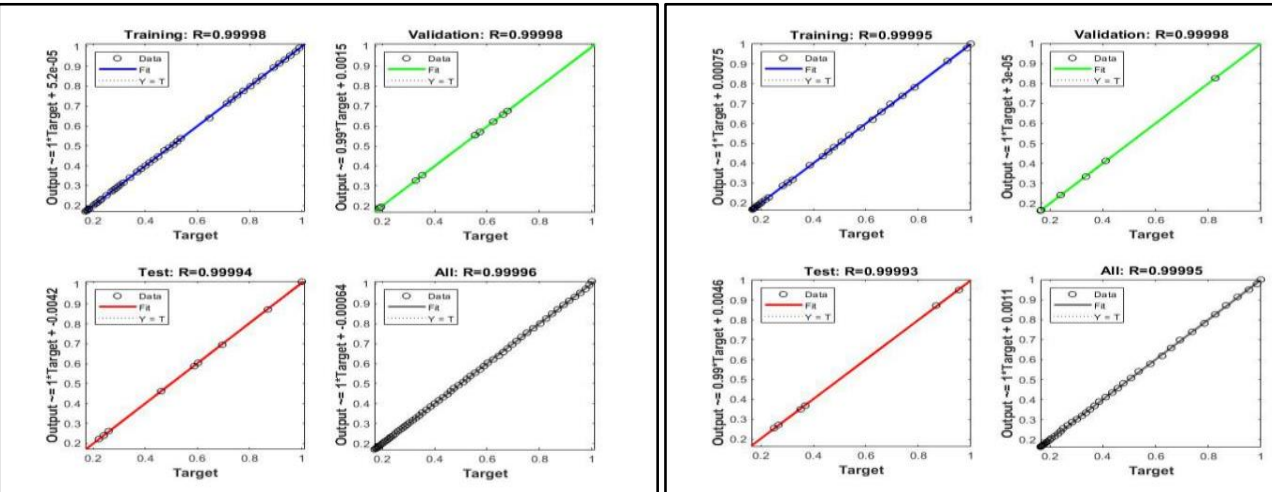

Fig. 6. Regression model for sundried bael pulp (BS)

Fig. 7. Regression model for hotair dried bael pulp (BH) 
Comparative Approach of Artificial Neural Network and Thin Layer Modelling for Drying Kinetics and Optimization of Rehydration Ratio for Bael (Aegle marmelos (L) correa) Powder Production

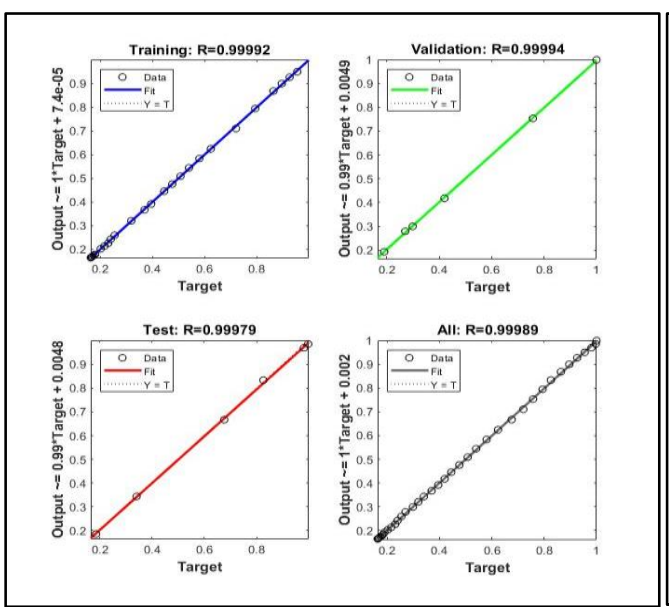

Fig. 8. Regression model for microwave dried bael pulp (BM)
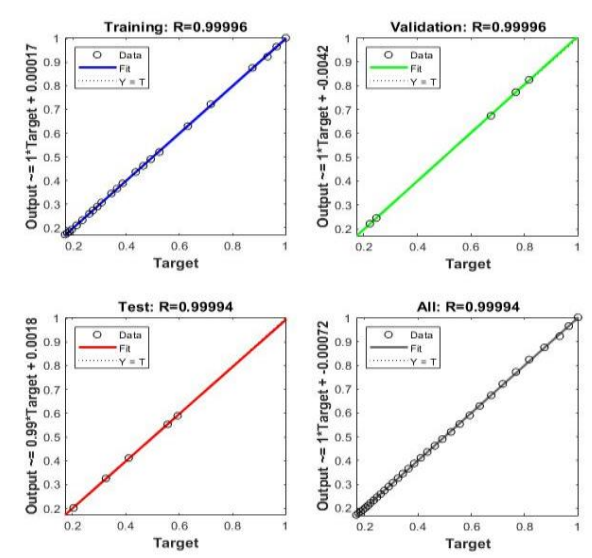

Fig. 9. Regression model for freeze dried bael pulp (BF)

\section{Validation of models}

The optimization methods were used to amplify the RR value for better reconstitution of bael powder produced. Additional experimental results were accomplished to confirm the projected processing conditions (Novotna 2020, Diaconeasa 2019). The $\mathrm{RR}$ at the projected process ambiance was 3.39 for $\mathrm{BS}, 4.5$ for $\mathrm{BH}, 5.51$ for $\mathrm{BF}$, and 4.7 for BM through RSM. All the investigational RR values were in the close vicinity with the projected outcomes. The percentage errors were $0.00 \%(\mathrm{BS}), 0.44 \%(\mathrm{BH})$, $0.18 \%(\mathrm{BF}), 0.21 \%(\mathrm{BM})$ and $0.00 \%(\mathrm{BS}), 2.44 \%(\mathrm{BH}), 3.08 \%(\mathrm{BF}), 1.49 \%(\mathrm{BM})$ for RSM model and PSO respectively in the event for validation of models predicted.

DOI: $10.24818 / 18423264 / 55.1 .21 .11$ 
Tanmay Sarkar, Molla Salauddin, Sudipta Kumar Hazra, Tanupriya Choudhury, Runu Chakraborty

Table 2. Effect of process factors on RR of bael powder

\begin{tabular}{|c|c|c|c|c|}
\hline $\begin{array}{l}\text { Method } \\
\text { of } \\
\text { drying }\end{array}$ & Response & Models & $\begin{array}{c}\mathrm{R}^{2} \\
\text { value }\end{array}$ & $\begin{array}{l}\text { Adjusted } \\
\mathrm{R}^{2} \text { value }\end{array}$ \\
\hline $\begin{array}{l}\text { Hot air } \\
\text { drying }\end{array}$ & $\begin{array}{c}\text { Rehydration } \\
\text { Ratio }\end{array}$ & $\begin{array}{l}\text { Rehydration Ratio }=+13.99616- \\
0.24488 \times \text { Temperature }-0.78594 \times \\
\text { Screen opening }+0.042950 \times \\
\text { Homogenisation Time }+9.875 \times 10^{-3} \\
\times \text { Temperature } \times \text { Screen opening }- \\
4.16667 \times 10^{-5} \times \text { Temperature } \times \\
\text { Homogenisation Time }+2.41667 \times \\
10^{-3} \times \text { Screen opening } \times \\
\text { Homogenisation Time } \\
+1.17928 \times 10^{-3} \times \text { Temperature } \\
+6.55844 \times 10^{-3} \times \text { Screen opening }{ }^{2}- \\
4.26542 \times 10^{-4} \times \text { Homogenisation } \\
\text { Time }^{2} \quad\end{array}$ & 0.9413 & 0.8886 \\
\hline $\begin{array}{l}\text { Micro- } \\
\text { wave } \\
\text { drying }\end{array}$ & $\begin{array}{c}\text { Rehydration } \\
\text { Ratio }\end{array}$ & $\begin{array}{l}\text { Rehydration Ratio }=+5.20248- \\
5.39853 \times 10^{-3} \times \text { Power level }+ \\
0.024330 \times \text { Screen opening }+ \\
4.18925 \times 10^{-3} \times \text { Homogenisation } \\
\text { Time }\end{array}$ & 0.9416 & 0.9306 \\
\hline $\begin{array}{l}\text { Freeze } \\
\text { drying }\end{array}$ & $\begin{array}{c}\text { Rehydration } \\
\text { Ratio }\end{array}$ & $\begin{array}{l}\text { Rehydration Ratio }=+3.52153 \\
+0.21059 \times \text { Screen } \text { opening } \\
+9.23917 \times 10^{-3} \times \text { Homogenisation } \\
\text { Time }\end{array}$ & 0.7144 & 0.6624 \\
\hline $\begin{array}{c}\text { Sun } \\
\text { drying }\end{array}$ & $\begin{array}{c}\text { Rehydration } \\
\text { Ratio }\end{array}$ & $\begin{array}{l}\text { Rehydration Ratio }=+3.75814- \\
0.73549 \times \text { Screen opening } \\
+4.70669 \times 10^{-3} \times \text { Homogenisation } \\
\text { Time }-4.83333 \times 10^{-3} \times \text { Screen opening } \\
\times \text { Homogenisation Time }+0.11125 \times \\
\text { Screen opening }{ }^{2}+4.16667 \times 10^{-4} \times \\
\text { Homogenisation Time } \\
\end{array}$ & 0.9676 & 0.948 \\
\hline
\end{tabular}


Comparative Approach of Artificial Neural Network and Thin Layer Modelling for Drying Kinetics and Optimization of Rehydration Ratio for Bael (Aegle marmelos (L) correa) Powder Production

\section{Conclusion}

Among the thirteen semi theoretical and empirical model studied the Midilli et al., model was found fitted best with the highest $\mathrm{R}^{2}$ value of 0.99964 for BS and 0.99964 for BF while the lowest $\chi^{2}$ of $2.41 \times 10^{-5}$ and $3.03 \times 10^{-5}$ was observed for BS and $\mathrm{BF}$ respectively. Hii et al., model was found superior in predicting the drying characteristics for $\mathrm{BH}$ and $\mathrm{BM}$ with the maximum $\mathrm{R}^{2}$ value of 0.99848 and 0.99987 in addition to minimum $\chi^{2}$ of $1.08 \times 10^{-4}$ and $8.74 \times 10^{-6}$ respectively. The $\mathrm{R}^{2}$ values for the ANN model were 0.99996, 0.99995, 0.99989, and 0.99994 for BS, BH, BM, and BF respectively. Wet-lab investigation and predicted observations showed that the PSO method may be an alternative practice for the food processing optimization. The maximum RR value for $\mathrm{BH}$ was attained at an oven temperature of $60^{\circ} \mathrm{C}$, homogenization time of 60 seconds, and 6 mesh size screen opening. The same for BM was reached at a microwave power level of 180 watt, 60 seconds of homogenization time, and 6 mesh screen opening. Homogenization time of 60 seconds and 6 mesh sized screen opening were observed to be the optimum condition to achieve the highest $\mathrm{RR}$ value for both $\mathrm{BS}$ and $\mathrm{BF}$. Though the RSM model is unable to predict BF with anticipated precision $\left(\mathrm{R}^{2}=0.7144\right)$ though the PSO method certainly seemed to build a more robust model $\left(\mathrm{R}^{2}=0.9751\right)$. Certainly, PSO provides a rapid optimized outcome of the optimize process variable on bael powder production, in comparison to traditional practice like RSM.

\section{REFERENCES}

[1]Hazra, S.K., Sarkar, T., Salauddin, M., Chakraborty, R. (2020), Characterization of Phytochemicals, Minerals and in Vitro Medicinal Activities of Bael (Aegle marmelos L.) Pulp and Differently Dried Edible Leathers. Heylion, 6(10);

[2] Onwude, D.I., Hashim, N., Janius, R., Nawi, N., Abdan, K. (2016), Evaluation of a Suitable Thin-Layer Model for Drying of Pumpkin under Forced Air Convection. International Food Research Journal, 23( 3): 1173-1181;

[3]Dash, K.K., Chakraborty, S., Singh, Y.R. (2020), Modeling of Microwave Vacuum Drying Kinetics of Bael (Aegle marmelos L.) Pulp by Using Artificial Neural Network. 101, 343-351;

[4]Sarkar, T., Salauddin, M., Hazra, S.K., Chakraborty, R. (2020), Effect of Cutting Edge Drying Technology on the Physicochemical and Bioactive Components of Mango (Langra Variety) Leather. Journal of Agriculture and Food Research.2;

[5]Han, Q-H., Yin, L-J., Li, S-J., Yang, B-N., Ma, J-W. (2010), Optimization of Process Parameters for Microwave Vacuum Drying of Apple Slices Using Response Surface Method. Drying Technology, 28(4): 523-532;

DOI: 10.24818/18423264/55.1.21.11 
Tanmay Sarkar, Molla Salauddin, Sudipta Kumar Hazra, Tanupriya Choudhury, Runu Chakraborty

[6]Adiletta, G., Wijerathne, C., Senadeera, W., Russo, P., Crescitelli, A., Matteo, M D. (2018), Dehydration and Rehydration Characteristics of Pretreated Pumpkin Slices. Italian Journal of Food Science, 30(4): 684-706;

[7]Alara, O., Nour, A., Afolabi, H., Olalere, O. (2018), Efficient Extraction of Antioxidants from Vernoniacinerea Leaves: Comparing Response Surface Methodology and Artificial Neural Network. Beni-Suef University Journal of Basic and Applied Sciences, 7(3): 276-285; [8]İş̧eroğlu, H., Turker, Izzet (2018), Thermal Inactivation Kinetics of Microencapsulated Microbial Transglutaminase by Ultrasonic Spray-Freeze Drying. LWT, 101: 653-662;

[9]El-Beltagy, A., Gamea, G.R., Essa, A.H.A. (2007), Solar Drying Characteristics of Strawberry. Journal of Food Engineering, 78(2): 456-464;

[10]Vega, A., Fito, P., Andr'es, A., Lemus, R. (2007), Mathematical Modeling of Hot-Air Drying Kinetics of Red Bell Pepper (var. Lamuyo). Journal of Food Engineering, 79(4): 1460-1466;

[11]Meisami-asl, E., Rafiee, S. (2009), Mathematical Modeling of Kinetics of Thin Layer Drying of Apples (Golab). Agricultural Engineering International: The CIGR e-Journal, 6: 110 ;

[12]Midilli, A., Kucuk, H., Yapar, Z. (2002), A New Model for Single-Layer Drying.Drying Technology, 20(7): 1503-1513;

[13]Hii, C.L., Law, C.L., Cloke, M. (2009), Modeling Using a New Thin-Layer Drying Model and Product Quality of Cocoa. Journal of Food Engineering, 90(2): 191-198; [14]Akpinar, E.K. (2006), Mathematical Modeling of Thin-Layer Drying Process under Open Sun of Some Aromatic Plants. Journal of Food Engineering, 77(4): 864-870;

[15]Omolola, A.O., Jideani, A.I.O., Kapila P.F. (2014), Modeling Microwave-Drying Kinetics and Moisture Diffusivity Of Mabonde Banana Variety. International Journal of Agricultural and Biological Engineering, 7(6): 107-13;

[16]Gan P.L., Poh, P.E. (2014), Investigation on the Effect of Shapes on the Drying Kinetics and Sensory Evaluation Study of Dried Jackfruit. International Journal of Science and Engineering, 7(2): 193-198;

[17]PerieiraDa Silva, W., Silva, C.M.D.P.S., De Sousa, J.A.R., Farias, V.S.O. (2013), Empirical and Diffusion Models to Describe Water Transport into Chickpea (Cicerarietinum L.). International Journal of Food Science and Technology, 48(2): 267-73;

[18] Yaldiz, O., Ertekin, C., Uzun, H.I. (2001), Mathematical Modeling of Thin-Layer Solar Drying of Sultana Grapes.Energy, 26(5): 457-65;

[19]Demir, V.Ã., Gunhan, T., Yagcioglu, A.K. (2007), Mathematical Modeling of Convection Drying of Green Table Olives. Biosystem Engineering, 98(1): 47-53;

[20]Dash, K.K., Gope, S., Sethi, A., Doloi, M. (2013), Star fruit slices, International Journal of Agriculture. Food Science and Technology, 4(7): 679-686;

[21]Novotná, M. (2020), The Impact of Industry and Business Entity Type on Corporate Survival. Economic Computation and Economic Cybernetics Studies and Research; Faculty of Economic Cybernetics, Statistics and Informatics, 54(1): 97-112;

[22]Diaconeasa, M.C., Popescu, G., Boboc, D. (2019), Sustainable Food Consumption in the Web of Science Abstracts. Economic Computation and Economic Cybernetics Studies and Research, Faculty of Economic Cybernetics, Statistics and Informatics, 53(1): 299-307. 